\title{
NOVAS TECNOLOGIAS E MUTAÇÕES REGULATÓRIAS NOS TRANSPORTES PÚBLICOS MUNICIPAIS DE PASSAGEIROS: UM ESTUDO A PARTIR DO CASO UBER.
}

\section{NEW TECHNOLOGIES AND REGULATORY CHANGES IN MUNICIPAL PASSENGER TRANSPORTATION: A STUDY FROM THE UBER CASE.}

\author{
Gustavo Binenbojm ${ }^{1}$
}

\section{Resumo}

O presente estudo tem por objetivo analisar os efeitos disruptivos do fenômeno UBER sobre a regulação do mercado de transporte individual de passageiros, em especial o mercado de táxi. Em suma, o texto sustenta que a nova tecnologia associada a novas formas de gerenciamento criaram um novo modelo de negócios que supera, em termos de eficiência e bem-estar dos consumidores, a regulação estatal dos serviços de táxi.

Palavras-chave: transporte individual de passageiros; regulação; táxi; UBER.

\section{Abstract}

This article aims to analyze the disruptive effects of UBER phenomenon upon the regulation of individual transportation market, specially the taxi market. In sum, the text advocates the idea that the new technology in association with a new management form has cretaed a new business model that overcomes, in terms of efficiency and consumer welfare, state taxi regulations.

Keywords: individual transportation of passengers; taxi; UBER.

\footnotetext{
${ }^{1}$ Professor Titular de Direito Administrativo da Faculdade de Direito da Universidade do Estado do Rio de Janeiro - UERJ. Doutor em Direito Público, UERJ. Master of Laws (LL.M.), Yale Law School (EUA). Professor Emérito da Escola da Magistratura do Estado do Rio de Janeiro - EMERJ. E-mail: gustavo.binenbojm@bgcb.adv.br
} 


\section{INTRODUÇÃO: O CASO UBER E SEU EFEITO DISRUPTIVO SOBRE A REGULAÇÃO DOS MEIOS DE TRANSPORTE INDIVIDUAL DE PASSAGEIROS.}

O presente estudo tem por objetivo analisar o fenômeno UBER e seu efeito disruptivo sobre a regulação dos serviços de transporte individual de passageiros. O caso é especialmente interessante porque nele se apresenta toda a complexidade do processo regulatório, inclusive a resistência dos taxistas - participantes exclusivos, até então, do mercado de transporte individual de passageiros - diante da ampliação da oferta de serviços similares por terceiros, viabilizada em razão do surgimento de inovação tecnológica que permite o compartilhamento eletrônico de informações e do desenvolvimento de um novo modelo de negócios, que tem sido denominado de economia compartilhada (sharing economy). ${ }^{2}$

O fenômeno UBER será a seguir exposto como um estudo de caso. De acordo com a Constituição brasileira de 1988, a União tem competência privativa para legislar sobre "diretrizes da política nacional de transportes" e "trânsito e transporte" (art. 22, IX e XI). Nesse sentido, foram editadas a Lei federal $n^{\circ}$ 12.587/2012, que trata da Política Nacional de Mobilidade Urbana, e a Lei federal $n^{\circ} 12.468$, de 2011, que regulamenta a profissão de taxista. Em ambas as leis há a previsão de que a "a utilização de veículo automotor, próprio ou de terceiros, para o transporte público individual remunerado de passageiros" é privativa de taxistas.

O mercado de táxis opera em três segmentos: (i) o segmento de pontos de táxi, conhecido na literatura internacional como taxi rank; (ii) o segmento de rua, chamado de hailing; e (iii) o segmento porta a porta, também conhecido como pre-booking, taxi-booking ou phone booking, no qual também operam os provedores de serviços de caronas pagas. ${ }^{3}$ A prevalência de cada modalidade do serviço varia de cidade para cidade ao redor do mundo. Em geral, centros urbanos

\footnotetext{
2 Os estudos iniciais de "economia compartilhada" começam a ganhar destaque em 1978 com o trabalho de FELSON, Marcus \& SPAETH, Joe L. Community Structure and Collaborative Consumption: a routine activity approach. In: American Behavioral Scientist, vol. 21, no 4, Março/Abril, 1978, pp. 614/624. Os autores se referem a atos de "consumo colaborativo" para designar "eventos nos quais uma ou mais pessoas consomem bens ou serviços em um processo econômico de se engajar em atividades comuns. " (Ibid., p. 614).

${ }^{3}$ V. Organization for economic Cooperation and Development (OECD). Competition Committee. Taxi Services Regulation and Competition. Roundtables on Competition Policy no 81, Paris, Out. 2007, p. 18: "Taxis are small passenger vehicles providing point-to-point personal transport services. In this general context, the taxi market can be further divided into three broad categories: the rank, hail and prebooked markets. Taxi ranks are designated places at which taxis may queue to await passengers, and vice versa. Passengers are generally expected to take the first cab at a rank. The hail market comprises situations in which consumers hail a cruising taxi on the street. In the pre-booked a market, consumers telephone for a taxi, whether for immediate dispatch or for dispatch at a later time".
} 
densamente povoados, como Rio de Janeiro e São Paulo, apresentam grande proporção de táxis dos dois primeiros segmentos, ao passo que cidades com menos habitantes, como municípios do interior do País, tendem a ser dominadas pela modalidade porta a porta.

Tradicionalmente a racionalidade regulatória do serviço de táxi é apresentada a partir de quatro principais preocupações: (i) redução da assimetria de informação (dados os altos custos de transação envolvidos na identificação e na escolha pelo usuário do seu transportador) (ii) garantia de segurança na atividade; (iii) melhoria na qualidade do serviço; e (iv) controle de externalidades negativas (poluição ambiental e congestionamento urbano). ${ }^{4}$ Informado por tais objetivos, o Poder Público tem historicamente submetido o mercado de táxi a um intenso controle regulatório, marcado que é pela disciplina jurídica de variáveis econômicas centrais para o exercício da atividade, tais como entrada, preço, qualidade e segurança. É neste sentido que o serviço de táxi configura uma modalidade de transporte público individual de passageiros, isto é, uma atividade econômica em sentido estrito, sujeita a intensa regulação estatal, mas não um típico serviço público, como são os diferentes modais de transporte público coletivo de passageiros.

A fiscalização de entrada é apresentada como medida voltada a reduzir o impacto de externalidades negativas (pelo controle do volume de tráfego urbano e dos níveis de poluição ambiental) e a garantir a segurança de usuário e terceiros (ao permitir a verificação da habilitação técnica e da idoneidade moral dos condutores, além das condições de funcionamento dos veículos). O tabelamento de preços de preços volta-se a mitigar as assimetrias de informação e os altos custos de transação que oneram o usuário do serviço. ${ }^{5}$ Já os indicadores de performance buscam otimizar a qualidade do serviço e a segurança no exercício da atividade, estipulando, por exemplo, tempo máximo de rodagem dos automóveis, testes periódicos do veículo, regularidade

\footnotetext{
${ }^{4}$ V. GWILLIAM, Kenneth M. Regulation of Taxi Markets in Developing Countries: Issues and Options. Transport Notes, Urban Transport Thematic Group, The World Bank, Washington/DC, No. TRN-3, fev. 2005. Disponível em: http://www.taxi-library.org/trn-3_taxi_reg.pdf. Acessado em 01/10/2015. V., tb., RANKENA, Mark W; PAUTLER, Paul A. An Economic Analysis of Taxicab Regulation. U.S. Federal Trade Commission, 1984. Disponível em: https://www.ftc.gov/sites/ default/files/documents/reports/economic-analysis-taxicabregulation/23832.pdf. Acessado em 01/10/2015.

${ }^{5}$ Como explicam Carlos Emmanuel Joppert Ragazzo e Eduardo Frade Rodrigues, "o consumidor que busca um táxi normalmente não tem condições de pesquisar adequadamente os melhores preços e serviços disponíveis, como se estivesse transitando por lojas em um shopping center. Como não sabem quando outro táxi irá passar nem quanto esse outro motorista irá the cobrar, os potenciais passageiros dificilmente rejeitam o primeiro táxi que lhes é oferecido. Tal condição é ainda mais agravada no caso, por exemplo, de turistas, que não conhecem a cidade e seus serviços de táxi, ou na ocorrência de condições climáticas adversas". V. RAGAZZO, Carlos Emmanuel Joppert \& RODRIGUES, Eduardo Frade. Proporcionalidade e melhora regulatória a regulação dos serviços de táxi. In: Revista do IBRAC, no 22, 2013, p. 287.
} 
do taxímetro, identificações no automóvel, verificação rotineira de antecedentes criminais do motorista, exames médicos, limites de idade, dentre outros requisitos.

Devido à natureza pública do transporte de passageiros realizado pelos taxistas, as questões fundamentais que constituem o objeto de controvérsia estão postas da seguinte forma: o transporte privado individual de passageiros, não sujeito à outorga de autorizações específicas pelo Poder Público, é proibido pela legislação brasileira? Uma lei ordinária poderia instituir o monopólio dessa atividade econômica? É possível interpretar normas regulatórias infraconstitucionais em sentido contrário aos princípios constitucionais da livre iniciativa, da livre concorrência e da liberdade de exercício profissional? Quais as consequências jurídicas, sobre os marcos regulatórios até então vigentes, da superação empírica, pelos próprios mercados regulados, de antigas falhas que justificaram a intervenção estatal original? É possível falar-se numa verdadeira regulação disruptiva produzida pelo fenômeno UBER?

\section{A NATUREZA DA REGULAÇÃO DO SERVIÇO DE TRANSPORTE INDIVIDUAL DE PASSAGEIROS. DISTINÇÕES EM RELAÇÃO AOS SERVIÇOS DE TRANSPORTE COLETIVO DE PASSAGEIROS, VERDADEIROS SERVIÇOS PÚBLICOS.}

Em primeiro lugar, impõe-se reconhecer que a atividade de prestação do serviço de transporte individual de passageiros, quando tomada em sentido amplo, não é exclusiva de taxistas. Enquanto a Lei $n^{\circ}$ 12.468/2011 se destina apenas a quem detém a condição jurídica de taxista, a Lei $n^{\circ} 12.587 / 2012$, por sua vez, estabelece as diretrizes normativas que norteiam as políticas públicas para o setor, que incluem, de forma clara, os meios privados de transporte de passageiros no âmbito das políticas públicas para o transporte urbano (arts. $3^{\circ}, \S 2^{\circ}, 111$, e $4^{\circ}$, I). Esse segundo diploma legislativo, de escopo mais amplo que o primeiro, tem o claro objetivo de maximizar a disponibilidade e o acesso da população a meios de transporte individuais e privados.

Em segundo lugar, sob o prisma constitucional, a atividade de prestação do serviço de transporte individual de passageiros é atividade econômica em sentido estrito, e não serviço público, como as atividades de transporte coletivo. Dessa forma, a lei ordinária não poderia validamente criar um novo monopólio de atividade econômica, além daqueles já compreendidos na Constituição Federal (CF, art. 177). Reputa-se, portanto, inconstitucional qualquer interpretação das leis citadas acima no sentido da existência de um monopólio legal em favor dos taxistas. ${ }^{6}$ De

\footnotetext{
${ }^{6}$ V., a propósito, o parecer de Daniel Sarmento, cujas conclusões coincidem com as afirmações ora expostas: SARMENTO, Daniel. Ordem Constitucional Econômica, Liberdade e Transporte Individual de Passageiros: 0
} 
outro lado, ainda que se admita a disciplina legal do serviço de táxi como serviço público (o que nos parece uma opção jurídica válida), ele jamais poderia ser exclusivo, porque ausente qualquer razão legítima a justificar a vedação à exploração do transporte individual de passageiros como atividade econômica (assimetria regulatória). Eventual lei que instituísse a aludida exclusividade criaria hipótese odiosa e inconstitucional de restrição regulatória à livre concorrência. ${ }^{7}$

No âmbito dos serviços públicos típicos, todavia, as escolhas regulatórias ganham complexidade. É que os serviços públicos estão diretamente vinculados à satisfação de direitos fundamentais ${ }^{8}$ e envolvem vetores como a universalização, continuidade e modicidade tarifária. Esses fatores, por vezes, impõem e justificam a derrogação da lógica de mercado das normas de direito privado, como meio para tornar possível o acesso dos indivíduos às utilidades essenciais que compõem o rol de seus direitos fundamentais.

De fato, cabe ao Estado, em cada caso, ponderar os fatores que recomendam a adoção da concorrência com as preocupações relacionadas à indissociável relação entre os serviços públicos, a realização da dignidade da pessoa humana e a coesão social. ${ }^{9}$ A ponderação deve dar preferência àqueles valores que melhor se coadunarem com a concretização dos fins constitucionais pretendidos.

Assim, nem sempre a livre concorrência será o melhor caminho. Como destaca Alexandre dos Santos Aragão, "não apenas no âmbito dos serviços públicos, mas a fortiori na sua seara, a concorrência não é um valor em si mesmo, podendo constituir, outrossim, um instrumento de realização eficiente dos objetivos dos serviços públicos. " 10 Só se deve privilegiar a concorrência enquanto ela for um meio adequado para assegurar tais objetivos.

Tenha-se em vista que as obrigações adicionais impostas ao concessionário do serviço público, relacionadas à universalização, continuidade e modicidade tarifária, têm - e não podem

\footnotetext{
'caso Uber'. Parecer. Disponível em: http://www.conjur.com.br/2015-jul-15/aplicativo-uber-nao-fere-leisbrasileiras. Acessado em: 15.07.2015.

${ }^{7}$ Sobre o tema, v. JORDÃO, Eduardo Ferreira. Restrições regulatórias à concorrência. Belo Horizonte: Fórum, 2009.

8 "A atividade de serviço público é um instrumento de satisfação direta e imediata dos direitos fundamentais, entre os quais avulta a dignidade humana. O serviço público existe porque os direitos fundamentais não podem deixar de ser satisfeitos. (...)

Todas as atividades estatais, mesmo as não administrativas, são um meio de promoção dos direitos fundamentais. Mas o serviço público é o desenvolvimento de atividades de fornecimento de utilidades necessárias, de modo direto e imediato, à satisfação de direitos fundamentais. Isso significa que o serviço público é o meio de assegurar a existência digna do ser humano. O serviço de atendimento a necessidades fundamentais e essenciais para a sobrevivência material e psicológica dos indivíduos. "8

${ }^{9}$ ARAGÃO, Alexandre Santos de. Direito dos Serviços Públicos. Rio de Janeiro: Forense, 2007, p. 421.

${ }^{10}$ ARAGÃO, Alexandre Santos de. Op. Cit., p. 421.
} 
deixar de ter, no regime capitalista - como contrapartida o possível estabelecimento de regime jurídico de privilégio na sua prestação. Assim, por exemplo, garante-se ao concessionário a preservação da equação econômica do contrato de concessão, como também, em diversos casos, pode ser necessário atribuir-se a exclusividade na exploração da atividade econômica em sentido amplo que constitui o seu substrato. Vale dizer: serviços públicos podem ser exclusivos ${ }^{11} \mathrm{e}$, em determinados casos, a exclusividade é medida necessária para viabilizar a sua prestação de forma satisfatória.

Um exemplo dessa constatação encontra-se nos casos de monopólio natural (situação na qual a existência de um único agente atuando em determinado campo econômico pode trazer maiores benefícios à sociedade do que se houvesse um mercado amplo). Tome-se o exemplo dos serviços de distribuição de gás ou de energia elétrica. Os investimentos necessários à expansão de tamanha infraestrutura são altíssimos e, em boa parte dos casos, jamais poderiam ser efetuados num ambiente de livre concorrência. Em determinados lugares e condições, somente a exploração exclusiva do serviço pelo investidor é capaz de justificar os custos envolvidos e viabilizar a sua adequada prestação. Em casos que tais, a existência de regulação de entrada e a limitação do mercado a um ou a um determinado número de players, por exemplo, é a medida mais adequada a ser adotada pelo ente regulador.

Sobre o tema, Floriano de Azevedo Marques Neto comenta que:

"quando tratamos de utilidades públicas, a regulação econômica não pode se pautar apenas pelo prisma da competicão. Os interesses da sociedade (os móveis da regulação estatal) enredados nessa atividade não são exclusivamente traduzidos por critérios de eficiência econômica tais como redução de custos e livre opção pelos usuários. Há toda uma gama de interesses de universalização e de perenidade na fruição destes serviços (porquanto se considere ser relevante para a coletividade que, como meta, todos os indivíduos possam se servir dessa utilidade) que justificam a preterição, ao menos transitória, de um regime de competição plena o qual tende a beneficiar sempre a parcela dos consumidores efetivos, em detrimento dos consumidores potenciais do serviço. (...) Privilegiar o vetor do benefício competitivo quando majoritariamente apropriado pelos consumidores hipersuficientes, em detrimento do aumento da base dos que podem usufruir de uma atividade essencial, viola tanto os princípios e objetivos fundamentais da República (cf. art. 10, 11 e III e art. 30, I, III e IV),

\footnotetext{
${ }^{11}$ V. STF, ADPF n 46, voto do Ministro Eros Grau, p. 4: "Os regimes jurídicos sob os quais são prestados os serviços públicos importam em que sua prestação seja desenvolvida sob privilégios, inclusive, em regra, o da exclusividade na exploração da atividade econômica em sentido amplo a que corresponde a sua prestação. É justamente a virtualidade desse privilégio de exclusividade na prestação, aliás, que torna atrativo para o setor privado a sua exploração, em situação de concessão ou permissão". V. tb GRAU, Eros Roberto. A ordem econômica na Constituição de 1988, São Paulo: Malheiros, 2005.
} 
quanto os axiomas estruturantes da Ordem Econômica (cf. art. 170, caput e incisos III e VIII). "12

Pode, assim, haver razões jurídicas, econômicas e técnicas que justifiquem a adoção, em certos casos, lugares e momentos históricos, de medidas restritivas ao acesso de certos agentes ao mercado. É nesse contexto que se enquadra o objeto da presente análise. Embora a regra, no âmbito do serviço público, seja a adoção de um modelo de ampla competição (não exclusividade), nada impede que essa lógica seja afastada em razão de outros fatores, que indiquem que os fins perseguidos serão mais bem atendidos com a adoção de um modelo distinto.

Com efeito, as Constituições da República e Estadual admitem esse tipo de ponderação, porque não a vedam. A prova disso é que mesmo a Lei Federal no 8.987/97 (art. 16) e a Lei Estadual no 2.831/97 (art. 5ㅇ), das quais se extrai a regra geral da não exclusividade, admitem expressamente a concessão em regime de exclusividade nos casos de inviabilidade técnica ou econômica justificada.

E, de fato, mais do que ser lícito, é necessário que o legislador infraconstitucional defina um sistema normativo flexível o bastante para admitir exceções, sobretudo quando se trata da prestação de serviços públicos essenciais. Na hipótese do transporte público municipal, como visto, essa flexibilidade traduz-se na possibilidade de os Municípios, dentro de sua esfera própria de atuação (que envolve, como se viu no item anterior, o interesse local), analisarem a situação concreta e adotarem o regime jurídico que atenda, da melhor forma possível, as demandas constitucionais que incluem a busca por modicidade tarifária, universalização e qualidade dos serviços públicos.

Daí porque, como salienta Patrícia Sampaio, é possível, e até conveniente em alguns casos, a outorga de exclusividade ao prestador de determinado serviço público:

"O próprio art. 175, por outro lado, determina que a pessoa jurídica de direito público titular do serviço poderá delegá-lo a particulares, na forma da lei, mediante os institutos da concessão e da permissão de serviços públicos, após processo licitatório. A Lei Geral de Concessões e Permissões de Serviços Públicos (Lei n. 8.987/95), por sua vez, estabelece, em seu art. 16, que sempre que possível o serviço público seja concedido de modo não exclusivo, com vistas a propiciar a concorrência. (...) Dessa forma, não se pode desconsiderar que, se a opção politica do ente da federação for delegar o serviço ou atividade monopolizada mediante a outorga de exclusividade ao seu explorador, ter-se-á, no caso, uma concorrência "no mercado", já que, por decisão politica, existirá apenas um prestador do serviço durante o prazo de execução do contrato. Haverá, assim, a criação de poder econômico, para

12 MARQUES NETO, Floriano de Azevedo. Universalização de serviços públicos e competição: o caso da distribuição de gás natural. In: Revista de Direito Administrativo (RDA), v. 223, 2001, pp. 137 e 140; grifou-se. 
cuja disciplina o direito possui diversos instrumentos, tais como, controle tarifário, exigência de qualidade mínima da prestação, metas de universalização." 13

Assim, seria viável, a depender do contexto fático e dos objetivos estatais, instituir regime de exclusividade no modal de transporte coletivo de passageiros por ônibus, como estratégia regulatória para assegurar alguma forma de modicidade tarifária, mediante subsídio cruzado entre linhas deficitárias e superavitárias da cidade, por exemplo. Neste caso, a exclusividade seria uma forma de evitar o ataque oportunista apenas aos elos lucrativos da cadeia econômica. Realmente, o fato de haver grande disparidade entre linhas superavitárias e deficitárias, aliado à necessidade de universalização do serviço público e à persecução de modicidade tarifária podem justificar a criação de barreiras de entrada, mediante a exclusão de outros prestadores. Em um ambiente sem regulação, em que se operasse a livre concorrência, os agentes tenderiam a focar nos mercados mais rentáveis (fenômeno conhecido como "cherry picking", ou seja, realizar escolhas seletivas para operar apenas nas áreas consideradas as "cerejas do bolo"). Com isso, as demais áreas justamente as mais necessitadas - ficariam desassistidas, ou não seriam atendidas satisfatoriamente, muito menos a preços módicos.

No caso dos serviços de transporte individual de passageiros, entretanto, a lógica dos serviços públicos não se aplica. Mais que isso: ainda que se pretenda qualificá-los impropriamente como serviços públicos (serviços públicos impróprios), inexistem razões técnicas ou econômicas que possam justificar a sua prestação em regime de exclusividade.

\section{AS INOVAÇÕES TECNOLÓGICAS E GERENCIAIS DO FENÔMENO UBER.}

O UBER é um aplicativo (mobile app), disponível para download em smartphones, ${ }^{14}$ que permite a qualquer usuário requisitar um veículo de motorista profissional, previamente credenciado no UBER, para transporte individual de passageiros. O serviço prestado pelos agentes credenciados do UBER é similar ao serviço de transporte de passageiros em veículo a taxímetro (táxi). Originariamente, O UBER, em termos operacionais, adotava o modelo de negócio denominado "carona remunerada", através do qual o agente credenciado junto ao UBER, motorista profissional proprietário de veículo com as especificações mínimas exigidas pelo sistema, dava uma "carona" a potenciais interessados, previamente cadastrados.

\footnotetext{
13 SAMPAIO, Patrícia Regina Pinheiro. Regulação e concorrência: a atuação do CADE em setores de infraestrutura. São Paulo: Saraiva, 2013, pp. 209-211.

${ }^{14}$ Um smartphone é um telefone móvel que permite o acesso a programas executados através de sistema operacional. Tais programas são chamados de aplicativos (apps).
} 
Após a realização do transporte de passageiros, o usuário realiza o pagamento previamente estipulado por meio de cartão de crédito e o agente credenciado recebe uma remuneração pelo serviço prestado diretamente do UBER, que é destinatário de percentual do pagamento efetuado pelo passageiro. Entretanto, o modelo inicial de "caronas remuneradas" superou expectativas devido à qualidade do serviço de transporte de passageiros prestado pelos agentes credenciados do UBER, o que inclui automóveis mais novos e luxuosos, motoristas mais bem vestidos e solícitos, além de preços verdadeiramente competitivos. Assim, o UBER fidelizou parte da demanda por transporte individual de passageiros, insatisfeita, por diversos motivos, com os serviços prestados pelos taxistas.

Em verdade, a grande revolução no mercado de transporte individual de passageiros ocorreu com o desenvolvimento de aplicativos (apps) em smartphones para centrais de táxis, que são sistemas cuja função é a de permitir a requisição de um automóvel com motorista pelo usuário sem a necessidade de (i) ligação telefônica para centrais de atendimento, (ii) ligação direta para o taxista ou (iii) realização de sinal em via pública. ${ }^{15}$

Nessas novas circunstâncias geradas pela inovação tecnológica proporcionada pela criação dos apps, houve um impacto relevante na forma de relacionamento e compartilhamento de informações entre taxistas e usuários, com grande benefício econômico imediato para os motoristas que aderiram ao credenciamento efetuado pelos gestores dos apps, por dois motivos principais.

Em primeiro lugar, tais aplicativos foram muito bem recebidos pelos usuários devido à facilidade de uso e ao acesso rápido aos táxis, sobretudo em cidades nas quais a oferta do serviço era precária. Em segundo lugar, o app permitiu ao motorista se comprometer com pedidos de transporte de passageiros segundo critérios geográficos de proximidade e de forma imediata. Desse modo os pedidos são programados rapidamente e sem a necessidade de procurar clientes nas ruas, gerando economia de combustível e multiplicação dos serviços prestados.

Consequentemente, os taxistas vinculados aos apps de centrais de táxi passaram a lucrar mais, já que os ganhos de eficiência decorrentes do uso do aplicativo não foram repassados aos preços praticados porque sujeitos a tabelamento - regulação de preços - e, simultaneamente, não houve impacto direto ou exigências regulatórias adicionais de melhoria da qualidade do serviço prestado.

15 "EasyTaxi" e "99Taxis" são exemplos publicamente conhecidos de apps de centrais de taxi e até hoje são contestados, inclusive, por alguns taxistas que não aderiram aos mecanismos de gestão de informação dos referidos aplicativos.

Revista de Direito da Cidade, vol. 08, no 4. ISSN 2317-7721 pp. 1690- 17061698 
Pois bem: E o UBER? O UBER utilizou a mesma tecnologia que viabilizou a criação dos apps de centrais de táxi, embora tenha lançado um modelo de negócios diferenciado que se dispõe a oferecer um serviço de transporte individual de passageiros com maior qualidade. Ao contrário do táxi, O UBER fornece ao potencial usuário diversas informações relevantes, notadamente (i) informações sobre o perfil do motorista, (ii) grau de segurança e conforto de veículo, (iii) trajeto a ser percorrido e (iv) estimativa de preço, diminuindo intensamente assimetrias de informação relacionadas à qualidade do serviço a ser prestado. Vale registrar que o aplicativo fornece ainda a avaliação dos usuários daquele motorista especificamente designado para atendimento ao consumidor do serviço (sistema de scoring).

Por isso, o agente credenciado do UBER tem forte incentivo a prestar o melhor serviço de transporte possível, já que está sujeito a um sistema de credenciamento mais rigoroso e seu desempenho é avaliado pelos usuários, o que beneficia a todos os potenciais consumidores. De fato, a construção de uma boa reputação pelo motorista, devidamente amparada pelas notas dadas pelos usuários anteriores, é elemento essencial de manutenção do credenciamento junto ao UBER.

Em linhas gerais, dentre as vantagens apontadas pelos usuários do UBER, afirma-se que: (i) os agentes credenciados possuem carros bem mais novos e confortáveis que os taxistas; (ii) há maior qualidade, pontualidade e cortesia do atendimento; (iii) há a possibilidade de o usuário solicitar o estorno de cobranças indevidas por meio de canais eletrônicos de autoatendimento; e (iv) o pagamento pelo serviço é mais fácil, pois o UBER fatura o serviço no cartão de crédito previamente cadastrado pelo usuário.

Adicionalmente, é possível afirmar que o sucesso do UBER não advém somente da maior qualidade do serviço de transporte prestado, mas também da insatisfação dos usuários do serviço prestado pelos taxistas. As reclamações em relação aos táxis são inúmeras. Além de críticas relativas à (i) sujeira dos veículos, à (ii) falta de educação do motorista, à (iii) falta de troco no caso de pagamento em dinheiro e a (iv) outras formas desconfortáveis de atuação do taxista em relação ao usuário, tal como a prática comum de não ligar o ar condicionado no verão para economizar combustível, a principal reclamação diz respeito à pouca disponibilidade dos taxistas em todos os horários do dia e em determinadas regiões da cidade, chegando a haver casos de recusas explícitas de taxistas para ir a determinadas localidades. 


\section{A REAÇÃO DO LOBBY DOS TAXISTAS: A TENTATIVA DE PRESERVAÇÃO DO MONOPÓLIO (OU EXCLUSIVIDADE) DOS SERVIÇOS E DE SUA REGULAÇÃO FALHA.}

Diante da nova realidade de mercado, os taxistas, insatisfeitos com a entrada e o sucesso ${ }^{16}$ do UBER, iniciaram um movimento público, intenso e hostil, de contestação. Além da pressão política pelo banimento do UBER e do uso de medidas judiciais destinadas a suspender o acesso ao aplicativo, há relatos na mídia de que os agentes credenciados junto ao UBER têm sofrido ameaças de agressão física e intimidações de toda ordem, inclusive de órgãos públicos de controle vinculados a Departamentos e Secretarias de transporte coletivo de passageiros.

Essa situação gerou, inclusive, uma representação administrativa proposta contra sindicatos e pessoas ligadas ao segmento de táxi e dirigida ao Conselho Administrativo de Defesa Econômica (CADE), na qual se alega: (i) o cometimento de sham litigation - uso abusivo de medidas judiciais destinadas a impedir a atuação de concorrentes no mercado -, (ii) incitação e recurso à violência e (iii) pressão excessiva perante o Poder Legislativo, solicitando-se uma medida preventiva de cessação de condutas anticompetitivas em desfavor dos requeridos. ${ }^{17}$

Analisadas as circunstâncias do caso UBER, percebe-se claramente o efeito impressionante que o desenvolvimento de aplicativos (apps) contendo sistemas de "economia compartilhada" (sharing economy) causou em uma estrutura regulatória rígida e relativamente estável até então, provocando um choque que põe em xeque a eficiência da estrutura regulatória até então adotada. Em outras palavras, o advento desse novo modelo de negócios, utilizado para facilitar o relacionamento entre motoristas e usuários do serviço de transporte individual de passageiros, afetou todas as bases regulatórias relacionadas ao modelo tradicional de concessão de outorgas de autorizações a taxistas. Até então, os taxistas gozavam de exclusividade na prestação do serviço de transporte individual de passageiros e a entrada de novos prestadores no mercado era - e ainda é - muito difícil, tendo em vista obstáculos burocráticos e limites no número de concessões de outorga de autorizações para táxi, arbitrariamente definidos nas legislações locais.

\footnotetext{
${ }^{16} \mathrm{O}$ sucesso do UBER tem atraído novos concorrentes. Recentemente, o aplicativo de localização geográfica por GPS "Waze", do Google, iniciou um projeto experimental semelhante ao UBER em Tel Aviv, em Israel, chamado "RideWith", que permite aos usuários o compartilhamento de caronas particulares, à semelhança do modelo original do UBER. V. CARVALHO, Lucas. Waze concorre com Uber e lança app de caronas em Israel. In: Exame. Publicado em 08.07.2015. Disponível em: http://exame.abril.com.br/tecnologia/noticias/waze-concorre-com-uber-e-lanca-app-de-caronas-em-israel. Acessado em 12.07.2015.

${ }^{17}$ SELIGMAN, Felipe \& GONÇALVES, Natália. A favor do Uber, universitários pedem ao Cade medida contra taxistas. In: Jota. Publicado em 08.07.2015. Disponível em: http://jota.info/a-favor-do-uber-universitariospedem-ao-cade-medida-contra-taxistas. Acessado em 12.07.2015.
} 
Bem organizados, os sindicatos de taxistas exercem lobby constante sobre políticos, o que explica as diversas isenções tributárias aos proprietários de táxis, bem como a manutenção das aludidas limitações no número de outorga de autorizações nas legislações locais que constituem indícios fortes de captura regulatória. A propósito, pode-se citar, a título exemplificativo, a Lei $\mathrm{n}^{\circ}$ 5.492/2012, do Município do Rio de Janeiro, que estipula um critério máximo de outorga de autorizações para táxis, correspondente à "proporção de um veículo para cada setecentos habitantes do Município" (art. $1^{\circ}$ ), além de proibir "a liberação de nova permissão até ser alcançada a proporcionalidade estabelecida no artigo anterior" (art. $2^{\circ}$ ) e excluindo a possibilidade de "a constituição de novas empresas que operem como locadora de veículos e taxímetro no Município do Rio de Janeiro" (art. $7^{\circ}$ ).

Trata-se, evidentemente, de barreira normativa à entrada - ou regulação de entrada limitadora da quantidade de serviço ofertado - de potenciais taxistas que não encontra respaldo em evidências empíricas sobre as reais necessidades percebidas no mercado. Por que um veículo para cada setecentos habitantes? Qual o fundamento empírico ou econômico para legitimar a razão "um veículo - setecentos habitantes"? O motivo é incerto. Porém, o que é certa é a existência - notória nos maiores Municípios - de um mercado secundário marginal operado por titulares de autorizações, em que as licenças são controladas por oligopólios de grupos empresariais que efetuam o "aluguel" dos táxis a terceiros interessados através do mecanismo de "diárias", o que sugere um forte indício de prática de sobrepreço no mercado de prestação de serviço de transporte público de passageiros por táxi, inclusive na previsão desnecessária da "bandeira 2". ${ }^{18}$

\footnotetext{
${ }^{18}$ Curiosamente, há uma notável escassez de informações públicas a respeito do conteúdo de estratégias regulatórias - adotadas pelos Municípios - aptas a identificar custos e benefícios da regulação aplicável ao mercado de prestação de serviço de transporte individual de passageiros. No entanto, devido à polêmica envolvendo O UBER, há relatos recentes, veiculados na mídia, que confirmam a existência de oligopólios empresariais de titulares de licenças de táxi, bem como a existência de um mercado secundário marginal de "aluguel" por "diárias". Nesse sentido, em relação ao Município do Rio de Janeiro, é importante citar matéria online do veículo de mídia "O Globo" no sentido de que "apenas três grupos controlam 55,8\% dos táxis de empresas na cidade". V. MAGALHÃES, Luiz Ernesto. Apenas três grupos controlam 55,8\% dos táxis de empresas na cidade: o Rio tem 15 empresas registradas na prefeitura. In: O Globo. Publicado em 14.08.2015. Disponível em: http://oglobo.globo.com/rio/apenas-tres-grupos-controlam-558-dos-taxis-de-empresas-nacidade-17179697\#ixzz3j0eBLgo3. Acessado em 30.08.2015. V., ainda, matéria online do jornal "Extra", que afirma haver "um grupo de quinze empresas de aluguel de táxis" que "fatura R\$ 6.700.000,00 (seis milhões e setecentos mil reais) por mês com as chamadas 'diárias'." MERGULHÃO, Alfredo. Grupo de 15 empresas de aluguel de táxis fatura R\$ 6,7 milhões por mês com diárias. In: Extra. Publicado em 14.08.2015. Disponível em: http://extra.globo.com/noticias/rio/grupo-de-15-empresas-de-aluguel-de-taxis-fatura-67-milhoes-pormes-com-diarias-17179548.html. Acessado em 15.08.2015.
} 
Aliás, como informado por Carlos Emmanuel Joppert Ragazzo, há estudos que sugerem a eliminação da regulação de entrada e de preços em relação aos taxistas, justamente porque não há argumentos empíricos de natureza econômica que a fundamentam. ${ }^{19}$ Por outro lado, o número de motoristas profissionais cadastrados no UBER não depende de qualquer autorização estatal e variará de acordo com a percepção dos potenciados interessados a respeito dos retornos econômicos esperados em caso de cadastramento e disponibilização aos usuários. Adicionalmente, é importante notar que o UBER opera mediante exigência de uso de carros com padrão mais elevado de conforto e os agentes credenciados não usufruem de isenções tributárias.

Além de haver barreiras à entrada, limitando-se a quantidade de táxis em circulação, a experiência tem mostrado que a fiscalização quanto à qualidade do serviço prestado pelos taxistas tem deixado a desejar, seja em razão do estado de conservação de alguns veículos seja em virtude da qualidade do atendimento direto ao usuário realizado pelo taxista (regulação de qualidade). Logo, o regime regulatório atual aplicável aos taxistas tem falhado na regulação de qualidade e sequer se tem notícia de propostas voltadas a viabilizar um sistema informatizado de avaliação de desempenho dos motoristas de táxi, à semelhança do que ocorre no UBER. De igual modo, não tem se notado, nas legislações municipais, estímulos direcionados à redução de assimetrias de informação no relacionamento entre taxistas e usuários.

A única informação disponível ao usuário é a exposição de um alvará de autorização para o uso de táxi no vidro frontal do veículo, que nada diz sobre o perfil do motorista, inclusive quando a requisição é efetuada mediante a utilização de apps de centrais de táxi. Isto é, a regulação de informação tem se mostrado também insuficiente em permitir que o usuário avalie, fiscalize e controle as qualidades do prestador de serviço de transporte por táxi.

Por fim, a lógica operacional de tabelamento de preços para remuneração dos taxistas (regulação por preços) deve ser motivo de algumas considerações. Regular preço pode ser um fator importante de eliminação de assimetrias de informação e de barganha em mercados de serviços relativamente homogêneos. No caso do táxi, sob uma perspectiva mais pragmática, usar o "táxi X" ou o "táxi Y" pode não fazer nenhuma diferença significativa. O só fato da regulação de preços, desacompanhada de uma efetiva regulação de qualidade e de informação, tende a não gerar incentivos à melhoria do serviço prestado, já que não há nenhuma recompensa em aprimorálo devido à rigidez do tabelamento.

${ }^{19}$ V. RAGAZZO, Carlos Emmanuel Joppert. Regulação jurídica, racionalidade econômica e saneamento básico. Rio de Janeiro: Renovar, 2011, p. 154. 
Em prol do arcabouço regulatório vigente, restam apenas argumentos voltados ao controle de externalidades negativas decorrentes da sobreutilização de veículos particulares nos centros urbanos. Poluição ambiental e congestionamentos ilustram custos externos impostos à coletividade por quem opta pelo transporte individual. Nesse contexto, é prioridade dos gestores municipais aperfeiçoar a racionalidade do transporte de passageiros no interior das cidades, o que, em regra, está associado a políticas de incentivo à substituição de modais individuais (públicos ou privados) por modais coletivos. Isso se dá, por exemplo, pela redução dos custos pecuniários (subsídios) e de oportunidade (aumento na velocidade de deslocamento) dos transportes coletivos e pela imputação de custos adicionais aos veículos que servem de transporte individual de passageiros.

É aí que as atuais barreiras à entrada no setor apresentam inconsistências. De fato, para lidar com externalidades há mecanismos regulatórios mais inteligentes do que a proibição. Como apontam João Manoel Pinho de Mello e Vinicius Carrasco, "é possível compatibilizar o UBER com a quantidade ótima de carros na rua. A melhor forma de se corrigir uma 'externalidade' negativa, como a causada pelo aumento de congestionamento, é colocando um imposto que faça os motoristas se confrontarem com os custos sociais que eles causam ao decidirem sair de carro". ${ }^{20}$ No mesmo sentido é a conclusão do Departamento de Estudos Econômicos do CADE (DEE/CADE). ${ }^{21}$ Em recente análise do setor, o órgão concluiu que "não há elementos econômicos que justifiquem a proibição de novos prestadores de serviços de transporte individual. Para além disso, elementos econômicos sugerem que, sob uma ótica concorrencial e do consumidor, a atuação de novos agentes tende a ser positiva". ${ }^{22}$

\footnotetext{
${ }^{20}$ MELLO, João Manoel Pinho de \& CARRASCO, Vinicius. O Uber e a natureza da regulamentação. In: Exame. Publicado em 10.08.2015. Disponível em: http://exame.abril.com.br/rede-de-blogs/leis-daoferta/2015/08/10/o-uber-e-a-natureza-da-regulamentacao/. Acessado em 01/10/2015.

${ }^{21}$ O art. 17 da Lei no 12.529/2011 confere ao DEE/CADE competência para "elaborar estudos e pareceres econômicos, de ofício ou por solicitação do Plenário, do Presidente, do Conselheiro-Relator ou do Superintendente-Geral, zelando pelo rigor e atualização técnica e científica das decisões do órgão".

${ }^{22}$ V. O Mercado de Transporte Individual de Passageiros: Regulação, Externalidades e Equilíbrio Urbano. Documento de Trabalho 01/2015 (Setembro). Departamento de Estudos Econômicos (DEE). Conselho Administrativo de Defesa Econômica - Ministério da Justiça. Disponível em: http://www.cade.gov.br/upload/O\%20Mercado\%20de\%20Transporte\%20Individual\%20de\%20Passageiros.p df. Acessado em 01/10/2015. O estudo integra o processo no 08700.008971/2015-15, instaurado de ofício pelo próprio DEE.
} 


\section{OS EFEITOS DA REGULAÇÃO DISRUPTIVA PRODUZIDA PELO FENÔMENO UBER: ENTRE A PROTEÇÃO DESTRUTIVA E A DESTRUIÇÃO CRIATIVA.}

O caso UBER permite visualizar as diversas interações que ocorrem entre os elementos da regulação. À evidência, os aplicativos com sistemas de "economia compartilhada" (sharing economy) vieram para ficar, sendo possível afirmar que o UBER e os aplicativos rivais que virão tendem a aumentar a concorrência de mercado nos nichos de usuários mais exigentes quanto à qualidade do serviço prestado. Em outras palavras, há uma pressão concorrencial positiva clara de melhoria na qualidade dos próprios serviços de táxis sem qualquer influência da regulação ora existente, podendo-se cogitar, inclusive, de eventual migração de taxistas para credenciamento direto junto ao UBER ou sistemas similares.

Em suma, o caso UBER mostra que (i) as barreiras à entrada devem ser estabelecidas na exata medida das necessidades sociais, a fim de não impedir dinâmicas concorrenciais que tendem a melhorar os produtos ou serviços ofertados em prol dos consumidores; (ii) regular preços não é trivial, pois há outros elementos regulatórios mutuamente relacionados, podendo a regulação converter-se em sobrepreço quando desvinculada da qualidade do serviço; e (iii) a informação prestada diretamente pelo consumidor induz comportamentos nos participantes do mercado, configurando incentivo mais eficaz do que a regulação estatal. A tudo isso se soma a inovação tecnológica e gerencial utilizada pelo modelo UBER, cujos efeitos disruptivos sobre os serviços de taxi contribuem, na verdade, para o desenvolvimento econômico e para o aprendizado da própria economia da regulação.

Como ensinou Joseph Schumpeter, os ciclos de desenvolvimento capitalista são deflagrados por empresários inovadores, em busca de rendas monopolísticas. Essas inovações tornam ultrapassadas tecnologias até então utilizadas e provocam transformações nos fatores de produção, por via da obsolescência da capacidade instalada e do aumento temporário do desemprego. ${ }^{23} \mathrm{O}$ progresso tecnológico levará a ganhos de produtividade e ao aumento da renda do trabalho, mas os custos de transição são inevitáveis. Em uma palavra: enquanto a proteção das

\footnotetext{
${ }^{23}$ SCHUMPETER, Joseph A. Captalism, socialism and democracy. New York \& London: Taylor \& Francis eLibrary, 2003, p. 83: "The opening up of new markets, foreign or domestic, and the organizational development from the craft shop to such concerns as U.S. Steel illustrate the same process of industrial mutation - if I may use that biological term - that incessantly revolutionizes the economic structure from within, incessantly destroying the old one, incessantly creating a new one. This process of creative destruction is the essential fact about capitalism." Disponível em http://digamo.free.fr/capisoc.pdf. Acessado em 29.09.2015.
} 
velhas formas de produção é destrutiva, a sua destruição por práticas e tecnologias inovadoras e criativas é a expressão do próprio desenvolvimento econômico e social.

O caso UBER é um exemplo paradigmático de que a destruição criativa deve se impor sobre a proteção destrutiva. ${ }^{24} \mathrm{~A}$ economia da regulação deve lançar luzes para orientar a atuação regulatória do Estado no sentido da maximização de objetivos socialmente desejáveis, mas também para revelar a obsolescência e a ineficiência de seu sistema de incentivos quando ele for superado em decorrência de inovações tecnológicas e gerenciais, que se revelem aptas a gerar níveis mais elevados de concorrência, eficiência e bem-estar para os consumidores.

\section{BIBLIOGRAFIA}

ARAGÃO, Alexandre Santos de. Direito dos Serviços Públicos. Rio de Janeiro: Forense, 2007, p. 421. GRAU, Eros Roberto. A ordem econômica na Constituição de 1988, São Paulo: Malheiros, 2005.

CARVALHO, Lucas. Waze concorre com Uber e lança app de caronas em Israel. In: Exame. Publicado em 08.07.2015. Disponível em: http://exame.abril.com.br/tecnologia/noticias/waze-concorre-comuber-e-lanca-app-de-caronas-em-israel. Acessado em 12.07.2015.

DEPARTAMENTO DE ESTUDOS ECONÔMICOS (DEE). O Mercado de Transporte Individual de Passageiros: Regulação, Externalidades e Equilíbrio Urbano. Documento de Trabalho 01/2015 (Setembro). Conselho Administrativo de Defesa Econômica - Ministério da Justiça. Disponível em: http://www.cade.gov.br/upload/O\%20Mercado\%20de\%20Transporte\%20Individual\%20de\%20Pass ageiros.pdf . Acessado em 01/10/2015.

FELSON, Marcus \& SPAETH, Joe L. Community Structure and Collaborative Consumption: a routine activity approach. In: American Behavioral Scientist, vol. 21, no 4, Março/Abril, 1978, pp. 614/624.

GWILLIAM, Kenneth M. Regulation of Taxi Markets in Developing Countries: Issues and Options. Transport Notes, Urban Transport Thematic Group, The World Bank, Washington/DC, No. TRN-3, fev. 2005. Disponível em: http://www.taxi-library.org/trn-3_taxi_reg.pdf. Acessado em 01/10/2015.

JORDÃO, Eduardo Ferreira. Restrições regulatórias à concorrência. Belo Horizonte: Fórum, 2009.

MAGALHÃES, Luiz Ernesto. Apenas três grupos controlam 55,8\% dos táxis de empresas na cidade: o Rio tem 15 empresas registradas na prefeitura. In: O Globo. Publicado em 14.08.2015. Disponível em: http://oglobo.globo.com/rio/apenas-tres-grupos-controlam-558-dos-taxis-de-empresas-nacidade-17179697\#ixzz3j0eBLgo3. Acessado em 30.08.2015.

${ }^{24}$ MESQUITA, Mário. Viva a proteção destrutiva. In: Valor Econômico. Publicado em 20.08.2015. 
MARQUES NETO, Floriano de Azevedo. Universalização de serviços públicos e competição: o caso da distribuição de gás natural. In: Revista de Direito Administrativo (RDA), v. 223, 2001, pp. 137 e 140

MELLO, João Manoel Pinho de \& CARRASCO, Vinicius. O Uber e a natureza da regulamentação. In: Exame. Publicado em 10.08.2015. Disponível em: http://exame.abril.com.br/rede-de-blogs/leis-daoferta/2015/08/10/o-uber-e-a-natureza-da-regulamentacao/. Acessado em 01/10/2015.

MERGULHÃO, Alfredo. Grupo de 15 empresas de aluguel de táxis fatura R\$ 6,7 milhões por mês com diárias. In: Extra. Publicado em 14.08.2015. Disponível em: http://extra.globo.com/noticias/rio/grupo-de-15-empresas-de-aluguel-de-taxis-fatura-67-milhoespor-mes-com-diarias-17179548.html. Acessado em 15.08.2015.

SAMPAIO, Patrícia Regina Pinheiro. Regulação e concorrência: a atuação do CADE em setores de infraestrutura. São Paulo: Saraiva, 2013, pp. 209-211.

SARMENTO, Daniel. Ordem Constitucional Econômica, Liberdade e Transporte Individual de Passageiros: O 'caso Uber'. Parecer. Disponível em: http://www.conjur.com.br/2015-jul15/aplicativo-uber-nao-fere-leis-brasileiras. Acessado em: 15.07.2015.

SELIGMAN, Felipe \& GONÇALVES, Natália. A favor do Uber, universitários pedem ao Cade medida contra taxistas. In: Jota. Publicado em 08.07.2015. Disponível em: http://jota.info/a-favor-do-uberuniversitarios-pedem-ao-cade-medida-contra-taxistas. Acessado em 12.07.2015.

RAGAZZO, Carlos Emmanuel Joppert. Regulação jurídica, racionalidade econômica e saneamento básico. Rio de Janeiro: Renovar, 2011, p. 154.

RAGAZZO, Carlos Emmanuel Joppert \& RODRIGUES, Eduardo Frade. Proporcionalidade e melhora regulatória a regulação dos serviços de táxi. In: Revista do IBRAC, no 22, 2013, p. 287.

RANKENA, Mark W; PAUTLER, Paul A. An Economic Analysis of Taxicab Regulation. U.S. Federal Trade Commission, 1984. Disponivel em: https://www.ftc.gov/sites/ default/files/documents/reports/economic-analysis-taxicab-regulation/23832.pdf. Acessado em 01/10/2015.

SCHUMPETER, Joseph A. Captalism, socialism and democracy. New York \& London: Taylor \& Francis e-Library, 2003, p. 83

Trabalho enviado em 16 de outubro de 2016.

Aceito em 31 de outubro de 2016. 